\title{
Desempenho e Composição Corporal de Frangos de Corte Alimentados com Diferentes Níveis de Proteína e de Aminoácidos ou com Livre Escolha das Dietas ${ }^{1}$
}

\author{
Ana Valeria Kolling ${ }^{2}$, Alexandre de Mello Kessler ${ }^{3}$, Andréa Machado Leal Ribeiro ${ }^{4}$
}

\begin{abstract}
RESUMO - Foi realizado um experimento com 600 frangos de corte (300 machos e 300 fêmeas) de 1 a 49 dias de idade. Foram usadas três dietas (D) experimentais, isoenergéticas $(3.000$ e $3.150 \mathrm{kcal} \mathrm{EM} / \mathrm{kg}$ nas fases inicial e de crescimento, respectivamente), porém com diferentes níveis de proteína bruta (PB) e um dos quatro primeiros aminoácidos (AA) essenciais (Lis, Met+Cis, Tre e Trip): D1, (controle): 22\%PB; D2, $24 \%$ de PB com AA 20\% a mais que D1 (altaPB+20\%AA) e D3: 20\% PB e AA 12\% a menos que D1 (baixaPB-12\%AA). Na fase de crescimento, as PB foram de 20, 22 e 18\% para D1, D2 e D3, respectivamente, mantidas as mesmas proporções em AA. Uma quarta dieta foi definida pelas aves por livre escolha entre as dietas extremas (D2 e D3). O delineamento adotado foi completamente casualizado, em esquema fatorial 2x4 (sexo x dietas), e cinco repetições de 15 aves por tratamento. A técnica do abate comparativo foi usada para ganho de gordura e proteína. Verificouse que as aves alimentadas com dietas baixaPB-12\%AA apresentaram pior CA, menor GP e menor ganho de proteína corporal. No entanto, houve melhor relação da proteína consumida com ganho de peso. Frangos recebendo dietas altaPB+20\%AA tiveram pior aproveitamento da proteína consumida, não mostrando superioridade em GP, peso de partes e de carcaça às aves do grupo controle ou livre escolha. Ganho em gordura e proteína também foram semelhantes entre esses três tratamentos. As aves com livre escolha mostraram-se aptas em selecionar sua própria dieta, apresentando desempenho e composição corporal semelhantes às aves do grupo controle. O pior desempenho da dieta com baixa proteína foi mais evidente na fase inicial que na fase de crescimento. Machos foram mais eficientes que as fêmeas em utilizar os nutrientes consumidos sobretudo na fase de crescimento.
\end{abstract}

Palavras-chave: composição corporal, eficiência alimentar, relações energia:proteína e aminoácidos

\section{Performance and Body Composition of Broilers Fed Different Protein and Amino Acid Levels or Free-Choice Diets}

\begin{abstract}
An experiment was carried out to evaluate the effect of diets with different protein levels and energy:protein ratio and amino acids on the performance and body composition of broilers ( 300 males and 300 females from 1 to 49 days of age), as well as the effect of these factors on the nutrients utilization efficiency. Three isoenergy experimental diets (D) were used (3000 and $3150 \mathrm{kcal} \mathrm{ME} / \mathrm{kg}$ for starter and growing phase, respectively) varying the levels of crude protein (CP) and the first 4 essential amino acids (AA) (lysine, methionine+cysteine, threonine and tryptophan): D1, control, with 22\%CP; D2: 24\%CP and 20\% more AA than D1 (HighCP+20\%AA) and D3, 20\% CP and 12\% less AA than D1 (LowCP-12\%AA). On the growing phase the CP were 20, 22 and 18\% for D1, D2 and D3, respectively, keeping the same AA proportion. A fourth diet was defined by free-choice between diets D2 and D3. Birds were alloted in a completely randomized design, in a $2 \mathrm{x} 4$ factorial (sex x diets) scheme and 5 replications of 15 birds each per treatment. Comparative slaughter technique was used for body fat and protein gain. Birds fed LowCP-12\%AA diets showed reduced feed conversion, gain and body protein gain, but better protein intake-to-gain ratio. Broilers fed HighCP+20\%AA diets had worse protein intake-to-gain ratio, but similar weight gain, cuts or carcass weight to control or free-choice birds. Fat and protein gain were similar among those 3 treatments. Free-choice birds showed the same performance and body composition of the control broilers. LowCP-12\%AA diet was worse for broilers in starter phase than in growing phase. Male broilers were more efficient than females using nutrients, specially in the growing phase.
\end{abstract}

Key Words: body composition, feed efficiency, energy:protein, amino acids ratio

\section{Introdução}

Rápido crescimento e alta capacidade de consumo alimentar são características que normalmente se correlacionam em um programa de melhoramento genético e, por isso, linhagens modernas de frangos de corte possuem, aparentemente, elevada capacidade de consumo a partir de certa idade, que pode ser associada à deposição acentuada de gordura corporal (Kessler, 1999). Em geral, dietas com altos teores de energia proporcionam carcaças mais gordas, enquanto dietas com alto teor de proteína ocasionam carcaças mais

\footnotetext{
1 Projeto financiado pela Faurgs (Fundação de Apoio da UFRGS).

2 Aluna de Pós-Graduação do Programa de Pós-Graduação em Zootecnia da UFRGS.

3 Departamento de Zootecnia da UFRGS - Av. Bento Gonçalves 7712, Porto Alegre, RS, CEP: 91540-000 (akessler@ufrgs.br).

${ }^{4}$ Departamento de Zootecnia da UFRGS - Bolsista do CNPq
} 
magras. Dietas com relações calórico-protéicas mais amplas (menos proteína) promovem maior consumo de energia ou ingestão deficiente de proteína. Por outro lado, para dietas com relações mais estreitas (mais proteína), o consumo de energia é menor, o crescimento magro é máximo e as carcaças são mais magras (Rosebrough \& Steele, 1985; Summers et al., 1988, Leeson \& Summers, 1997; Bartov, 1998). Reginatto et al. (2000) observaram que dietas com relações mais amplas entre energia e proteína não alteraram o ganho de peso, mas resultaram em pior conversão calórica. Segundo os autores, a redução nos níveis protéicos provocam aumento do consumo para alcance de máximo crescimento.

Trabalhos comprovam que aves podem escolherentre duas ou mais rações, optando por uma dieta que mais se aproxime de suas necessidades nutricionais. Yo et al. (1998) relatam que frangos de corte, ao escolherem entre dietas com nível de proteína acima e abaixo do sugerido pelo NRC (1994), mostraram-se aptos a seleção de uma dieta equilibrada às suas exigências nutricionais. Shariatmadari \& Forbes (1993) observaram que aves com livre escolha apresentaram taxa de crescimento similar às aves controle, sugerindo aptidão para suprir exigências para máxima retenção de tecido desengordurado.

O objetivo neste trabalho foi estudar o efeito de dietas com diferentes níveis de proteína e, portanto, diferentes relações energia:proteína a aminoácidos sobre o desempenho e a composição corporal de frangos de corte, bem como a influência destes fatores sobre a eficiência de utilização dos nutrientes. Quanto à avaliação da capacidade das aves em selecionarem dietas adequadas às exigências nutricionais, foi incluída a livre escolha entre a dieta reduzida nos níveis de proteína bruta (PB) e aminoácidos limitantes (AA) e a dieta com alto nível de $\mathrm{PB}$ e nível ainda mais alto de AA.

\section{Material e Métodos}

Oexperimento foi conduzido utilizando frangos de corte de 1 a 49 dias de idade (300 machos e 300 fêmeas), criados em baterias. Foram adotadas três dietas (D) experimentais com mesmo nível de energia $(3.000 \mathrm{kcal}$ $\mathrm{EM} / \mathrm{kg}$ e $3.150 \mathrm{kcal} \mathrm{EM} / \mathrm{kg}$ nas fases inicial e de crescimento, respectivamente), porém com diferentes níveis de proteína bruta (PB) e dos quatro primeiros aminoácidos (AA)essenciais (lisina, metionina+cisteína, treonina e triptofano): D1, controle, com PB de $22 \%$ e normal em AA; D2: 24\% de PB com 20\% a mais em AA que D1 (altaPB+20\%AA) e D3: $20 \%$ PB e $12 \%$ a menos em AA que D1 (baixaPB-12\%AA). Na fase de crescimento, as PB foram de 20, 22 e 18\% para D1, D2 e D3, respectivamente, mantidas as mesmas proporções em AA. Uma quarta dieta foi definida pelas aves por livre escolha entre as dietas extremas (D2 e D3).

A composição dos ingredientes e os níveis nutricionais das rações experimentais são apresentados na Tabela 1. As dietas foram formuladas a partir de um lote de ingredientes (milho, farelo de soja e glúten de milho) previamente analisados para PB, EEe aminoácidos (analisados no laboratório da Ajinomoto Biolatina Ind. e Com., em São Paulo, SP).

Foram abatidos seis pintos de um dia, para obtenção da composição corporal inicial. Aos 49 dias de idade, foi abatida uma ave por repetição, representando o peso médio da gaiola, para determinação do peso das partes (peito, pernas e carcaça), do teor de proteína corporal (carcaça + penas + vísceras) e da gordura corporal (carcaça+vísceras). Proteína e gordura corporal foram determinadas conforme técnicas descritas pela AOAC (1990). Os dados percentuais de proteína e de gordura corporal, rendimento de peito, coxa+perna e carcaça foram aplicados ao peso vivo médio da gaiola, para obtenção da composição corporal média da gaiola. Os ganho de proteína e gordura corporal foram estimados por meio da técnica de abate comparativo. As aves e as sobras de ração foram pesadas semanalmente para obtenção do ganho de peso médio (GP) e do consumo médio de ração $(\mathrm{CR})$ e para cálculo da conversão alimentar (CA). A dieta selecionada no tratamento com livre escolha foi calculada com base no consumo de cada uma das dietas oferecidas e da composição nutricional das mesmas. Empregou-se um delineamento completamente casualizado, em que foram testados o sexo e as quatro dietas (incluindo a dieta resultante da livre escolha), num arranjo fatorial $2 \times 4$, compondo oito tratamentos com quatro repetições de 15 aves. Os dados foram submetidos à análise de variância por intermédio do programa STATISTIX (Analytical Software, 1996) e as médias foram comparadas pelo teste Tukey a 5\% de significância .

\section{Resultados e Discussão}

A dieta selecionada pelos frangos do tratamento livre escolha, quando comparada à dieta controle, foi ligeiramente inferior em proteína bruta, porém superior em lisina, metionina+cistina, treonina e triptofano, para ambos os sexos (Tabela 2).

R. Bras. Zootec., v.34, n.1, p.98-103, 2005 
Tabela 1 - Composição percentual das dietas experimentais

Table 1 - Percentual composition of the experimental diets

\begin{tabular}{|c|c|c|c|c|c|c|}
\hline \multirow{4}{*}{$\begin{array}{l}\text { Ingredientes } \\
\text { Ingredients }\end{array}$} & \multicolumn{6}{|c|}{ Dietas (Diets) } \\
\hline & \multicolumn{2}{|c|}{ Controle } & \multicolumn{2}{|c|}{ BaixaPB-12\%AA $^{1}$} & \multicolumn{2}{|c|}{ AltaPB+20\% $\mathrm{AA}^{1}$} \\
\hline & Inicial & Crescimento & Inicial & Crescimento & Inicial & Crescimento \\
\hline & Starter & Growing & Starter & Growing & Starter & Growing \\
\hline Milho & 56,66 & 60,30 & 63,34 & 67,11 & 50,53 & 54,00 \\
\hline Corn & & & & & & \\
\hline Farelo de soja & 30,8 & 25,74 & 25,18 & 19,96 & 35,73 & 30,85 \\
\hline Soybean meal & & & & & & \\
\hline Glúten de milho & 6,00 & 6,00 & 6,00 & 6,00 & 6,00 & 6,00 \\
\hline Corn gluten meal & & & & & & \\
\hline Óleo de soja & 2,24 & 3,88 & 1,17 & 2,77 & 3,15 & 4,84 \\
\hline Soybean oil & & & & & & \\
\hline Fosfato bicálcico & 1,80 & 1,69 & 1,85 & 1,75 & 1,76 & 1,65 \\
\hline Dicalcium phosphate & & & & & & \\
\hline Calcário & 1,55 & 1,50 & 1,56 & 1,52 & 1,54 & 1,50 \\
\hline Limestone & & & & & & \\
\hline Sal & 0,47 & 0,47 & 0,47 & 0,47 & 0,47 & 0,47 \\
\hline Salt & & & & & & \\
\hline DL-Metionina & 0,15 & 0,10 & 0,09 & 0,06 & 0,29 & 0,22 \\
\hline DL-methionine & & & & & & \\
\hline L-Lisina HCL & 0,15 & 0,12 & 0,13 & 0,14 & 0,29 & 0,22 \\
\hline$L$-Lysine $H C L$ & & & & & & \\
\hline L-Treonina & 0,00 & 0,01 & 0,00 & 0,01 & 0,08 & 0,08 \\
\hline L-Threonine & & & & & & \\
\hline Cloreto de Colina & 0,05 & 0,06 & 0,08 & 0,08 & 0,03 & 0,04 \\
\hline Choline cloride & & & & & & \\
\hline Supl. Mineral & 0,10 & 0,10 & 0,10 & 0,10 & 0,10 & 0,10 \\
\hline Mineral mix & & & & & & \\
\hline Supl. Vitamínico & 0,03 & 0,03 & 0,03 & 0,03 & 0,03 & 0,03 \\
\hline Vitamin mix & & & & & & \\
\hline EM (kcal/kg) & 3000 & 3.150 & 3000 & 3.150 & 3000 & 3.150 \\
\hline$M E$ & & & & & & \\
\hline Proteína bruta (\%) & 22,00 & 20,00 & 20,00 & 18,00 & 24,00 & 22,00 \\
\hline Crude protein & & & & & & \\
\hline $\operatorname{Lisina}(\%)$ & 1,15 & 1,00 & 1,00 & 0,88 & 1,38 & 1,20 \\
\hline Lysine & & & & & & \\
\hline Metionina (\%) & 0,53 & 0,46 & 0,45 & 0,39 & 0,69 & 0,59 \\
\hline Methionine & & & & & & \\
\hline Cálcio (\%) & 1,05 & 1,00 & 1,05 & 1,00 & 1,05 & 1,00 \\
\hline Calcium & & & & & & \\
\hline P disponível (\%) & 0,45 & 0,42 & 0,45 & 0,42 & 0,45 & 0,42 \\
\hline Available P & & & & & & \\
\hline
\end{tabular}

Suplemento mineral (mineral mix): $40 \mathrm{mg} \mathrm{Fe}, 80 \mathrm{mg} \mathrm{Zn,} 80 \mathrm{mg} \mathrm{Mn}, 10 \mathrm{mg} \mathrm{Cu}, 0,7 \mathrm{mg} \mathrm{l} \mathrm{e} \mathrm{0,3} \mathrm{mg} \mathrm{Se} \mathrm{por} \mathrm{kg} \mathrm{de} \mathrm{ração} \mathrm{(per} \mathrm{kg} \mathrm{of} \mathrm{diet).} \mathrm{Suplemento}$ vitamínico inicial (starter vitamin mix): $10.000 \mathrm{UI}$ vit. A, $3.000 \mathrm{UI}$ vit. D3, $30 \mathrm{mg}$ vit. E, $3 \mathrm{mg}$ vit. K, $3 \mathrm{mg}$ vit. B1, $8 \mathrm{mg}$ vit. B2, $4 \mathrm{mg}$ vit. B6, $0,014 \mathrm{mg}$ vit. B12, $20 \mathrm{mg}$ ác. pantotênico (pantothenic acid), $50 \mathrm{mg}$ niacina (niacin), $2 \mathrm{mg}$ ácido fólico (folic acid) e $0,15 \mathrm{mg}$ biotina (biotin) por $\mathrm{kg}$ de ração (per $\mathrm{kg}$ of diet). Suplemento vitamínico crescimento (growing vitamin mix): $8.000 \mathrm{UI}$ vit. A, $2.000 \mathrm{UI}$ vit. D3, $20 \mathrm{mg}$ vit. E, 2 $\mathrm{mg}$ vit. K, $2 \mathrm{mg}$ vit. B1, $6 \mathrm{mg}$ vit. B2, 2,5 mg vit. B6, 0,012 mg vit. B12, $15 \mathrm{mg}$ ácido pantotênico (pantothenic acid), $35 \mathrm{mg}$ niacina (niacin), $1 \mathrm{mg}$ ácido fólico (folic acid) e 0,08 mg biotina (biotin) por kg de ração (per kg of diet).

As aves alimentadas com dieta menos protéicas (baixaPB-12\% AA) apresentaram GP e CA estatisticamente inferiores às do grupo controle na fase inicial, mas não no período de 21 a 49 dias (Tabela 3). Porém, no período total, esta inferioridade se manteve $(\mathrm{P}<0,05)$. Entre a dieta controle e as demais, foram observados GP e CA semelhantes. Em nenhum dos períodos, as aves diferiram em consumo de ração.
Bartov \& Plavinik (1998) verificaram que dietas com mais proteína proporcionaram melhor eficiência alimentar, não diferindo em consumo e ganho de peso, ao passo que Reginatto et al. (2000) observaram redução no $\mathrm{CR}$ em aves que consumiram dietas com 23 a $20 \%$ de $\mathrm{PB}$ e EM de $3.200 \mathrm{kcal} / \mathrm{kg}$ ou dietas com 21 a $18 \%$ de PB e EM de $2.900 \mathrm{kcal} / \mathrm{kg}$. A dieta obtida a partir da livre escolha promoveu GP e CA semelhantes à dieta 
Tabela 2 - Dieta selecionada pelas aves com possibilidade de livre escolha entre as dietas altaPB+20\%AA e baixaPB- $12 \%$ AA

Table 2 - Diet selected by free choice birds between highCP+20AA and lowCP-12AA

\begin{tabular}{lcccc}
\hline & \multicolumn{2}{c}{$\begin{array}{c}\text { Fase inicial } \\
\text { Starter phase }\end{array}$} & \multicolumn{3}{c}{$\begin{array}{c}\text { Fase de crescimento } \\
\text { Growth }\end{array}$} \\
\cline { 2 - 5 } $\begin{array}{l}\text { Nutrientes } \\
\text { Nutrients }\end{array}$ & $\begin{array}{c}\text { Macho } \\
\text { Male }\end{array}$ & $\begin{array}{c}\text { Fêmea } \\
\text { Female }\end{array}$ & $\begin{array}{c}\text { Macho } \\
\text { Male }\end{array}$ & $\begin{array}{c}\text { Fêmea } \\
\text { Female }\end{array}$ \\
\hline $\begin{array}{l}\text { Proteína bruta (\%) } \\
\text { Crude protein }\end{array}$ & 20,9 & 21,0 & 19,1 & 19,2 \\
$\begin{array}{l}\text { Lisina (\%) } \\
\begin{array}{l}\text { Lysine } \\
\text { Metionina (\%) }\end{array}\end{array}$ & 1,19 & 1,20 & 1,03 & 1,03 \\
$\begin{array}{l}\text { Methionine } \\
\text { Treonina (\%) } \\
\begin{array}{l}\text { Threonine } \\
\text { Triptofano (\%) }\end{array}\end{array}$ & 0,57 & 0,57 & 0,48 & 0,49 \\
Triptophan & 0,28 & 0,85 & 0,77 & 0,77 \\
\hline
\end{tabular}

controle, embora, na fase inicial, as aves tenham alcançado menor GP. Yo et al. (1998) inferem que a habilidade das aves em selecionar proteína é inata, uma vez que levam menos de 34 horas para se adaptarem à uma situação de livre escolha, selecionando uma dieta adequada às suas exigências. Neste experimento, parece ter havido atraso nesse ajuste, que foi mais claro após os 21 dias. As fêmeas, em relação aos machos, comeram menos e tiveram menor ganho de peso durante todo o período, porém apresentaram pior conversão alimentar somente a partir dos 22 dias (Tabela 3).

Para consumo de proteína bruta, houve diferença entre os tratamentos, tendo as aves da dieta baixaPB12\%AA consumido menos proteína que as demais, em ambas as fases (Tabela 4). Na fase inicial, essa diferença refletiu em menor ganho de peso e de proteína corporal (Tabela 5). Porém, na fase de crescimento, essas aves não diferiram estatisticamente do grupo controle em GP, apresentando melhor utilização da proteína dietética. Estes resultados sugerem que baixos níveis de AA e PB são mais prejudiciais na fase inicial que na fase de crescimento. Aves com altaPB $+20 \%$ AA consumiram mais proteína que as demais na fase inicial, porém, na fase de crescimento, não diferiram estatisticamente do grupo controle. Esta dieta, no entanto, proporcionou menor eficiência na utilização da proteína dietética para GP, sobretudo no período total, à semelhança do observado por Reginatto et al. (2000). O grupo com livre escolha apresentou consumo de proteína inferior ao grupo controle na fase inicial, porém se igualou na fase de crescimento. No entanto, para o período total, acabou demonstrando melhor relação $(\mathrm{P}<0,05)$ na transformação da proteína consumida em ganho de peso, explicada pelo menor consumo observado. Reginatto et al. (2000) também observaram que a redução da proteína dietética melhorou o uso da proteína consumida. A relação lisina ingerida:ganho de peso foi semelhante nas dietas controle, baixaPB-12\%AA e livre escolha, o que era esperado, uma vez que as três dietas mantiveram uma relação mais próxima entre $\mathrm{PB}$ e lisina. Entretanto, para o grupo altaPB $+20 \% \mathrm{AA}$, que não manteve a mesma relação entre $\mathrm{PB}$ e lisina, observouse a pior relação lisina ingerida:ganho de peso, tanto na fase inicial como na de crescimento.

Machos e fêmeas apresentaram respostas semelhantes até 21 dias de idade (Tabela 4). Após esta idade, machos consumiram mais proteína e com maior eficiência de transformação em ganho de peso. De acordo com Kessler (1999), machos apresentam altas taxas de deposição protéica até 28-35 dias, enquanto fêmeas têm máxima deposição até 21-28 dias, o que explica porque a fase de crescimento apresenta maiores diferenças na eficiência de transformação dos nutrientes com relação ao sexo. Não houve interação significativa $(\mathrm{P}>0,05)$ entre as dietas e o sexo das aves.

Quanto à composição corporal (Tabela 5), o consumo da dieta altaPB+20\%AA não resultou em maiores ganhos de carcaça ou de partes comparado ao da dieta controle. Isto se deve ao fato de as aves apresentarem uma limitação genética na deposição de proteína. Jackson et al. (1982) verificaram que acima de $24 \%$ de PB na dieta, não houve mais alteração na quantidade de proteína corporal. Estes resultados estão de acordo com os de Borges et al. (2002), que estudaram níveis de lisina total para frangos de corte machos, dos 22 aos 42 dias de idade, pela medição do desempenho e dos ganhos de carcaça, de proteína e peito, e encontraram como exigência o nível médio de 1,05\%, que é similar ao nível da dieta controle e daquela selecionada pelas aves neste experimento.

Houve aumento numérico no peso de peito, corroborando os trabalhos de Schutte \& Pack (1995) e Bartov \& Plavnik (1998), que observaram que o consumo moderadamente elevado de proteína e aminoácidos adequadamente balanceados pode originar incrementos na produção de carne nas linhagens modernas de frangos de corte. Com a dieta baixaPB-12\%AA, houve menor ganho em proteína, peito e carcaça, mas o ganho em gordura foi semelhante aos demais tratamentos. Existem vários trabalhos na literatura que demonstram que dietas

R. Bras. Zootec., v.34, n.1, p.98-103, 2005 
Tabela 3 - Ganho de peso (GP), consumo de ração (CR) e conversão alimentar (CA), de acordo com as fases experimentais e dieta oferecida

Table 3 - Weight gain (GP), feed intake (CR) and feed conversion (CA), according to the experimental phases and offered diets

\begin{tabular}{|c|c|c|c|c|c|c|c|c|c|}
\hline \multirow[t]{2}{*}{$\begin{array}{l}\text { Dietas } \\
\text { Diets }\end{array}$} & \multicolumn{3}{|c|}{$\begin{array}{l}1 \text { a } 21 \text { dias } \\
1 \text { to } 21 \text { days }\end{array}$} & \multicolumn{3}{|c|}{$\begin{array}{l}22 \text { a } 49 \text { dias } \\
22 \text { to } 49 \text { days }\end{array}$} & \multicolumn{3}{|c|}{$\begin{array}{l}1 \text { a } 49 \text { dias } \\
1 \text { to } 49 \text { days }\end{array}$} \\
\hline & GP & $\mathrm{CR}$ & $\mathrm{CA}$ & GP & $\mathrm{CR}$ & $\mathrm{CA}$ & GP & $\mathrm{CR}$ & $\mathrm{CA}$ \\
\hline $\begin{array}{l}\text { Controle } \\
\text { Control }\end{array}$ & $751 \mathrm{a}$ & 1104 & $1,47 b$ & $1966 \mathrm{ab}$ & 3907 & $1,99 \mathrm{ab}$ & $2716 a$ & 5011 & $1,84 b$ \\
\hline $\begin{array}{l}\text { BaixaPB-12\%AA } \\
\text { LowCP-12\%AA }\end{array}$ & $659 \mathrm{c}$ & 1089 & $1,66 a$ & $1883 b$ & 3907 & $2,08 \mathrm{a}$ & $2543 b$ & 4996 & $1,97 \mathrm{a}$ \\
\hline $\begin{array}{l}\text { AltaPB }+20 \% \text { AA } \\
H i g h C P+20 \% A A\end{array}$ & $756 a$ & 1100 & $1,46 b$ & $1978 \mathrm{a}$ & 3828 & $1,94 b$ & $2734 a$ & 4928 & $1,80 \mathrm{~b}$ \\
\hline $\begin{array}{l}\text { Livre escolha } \\
\text { Free choice }\end{array}$ & $710 \mathrm{~b}$ & 1059 & $1,49 b$ & $2013 a$ & 3978 & 1,98ab & $2723 a$ & 5038 & $1,85 b$ \\
\hline Fêmea & $695 a$ & $1057 \mathrm{a}$ & 1,52 & $1834 a$ & $\begin{array}{l}\text { exo }(\text { Sex } \\
3784 a\end{array}$ & $2,06 a$ & $2529 a$ & 4841a & $1,91 \mathrm{a}$ \\
\hline $\begin{array}{l}\text { Female } \\
\text { Macho } \\
\text { Male }\end{array}$ & $743 b$ & $1120 \mathrm{~b}$ & 1,51 & $2086 b$ & $4026 b$ & $1,93 b$ & $2829 b$ & $5146 b$ & $1,82 b$ \\
\hline
\end{tabular}

Médias seguidas por letras distintas na mesma coluna diferem $(P<0,05)$ pelo teste Tukey.

Averages followed in the column followed by different letters differ $(P<.05)$ by Tukey test.

Tabela 4 - Consumo de proteína (CPB) e relações entre proteína e lisina ingeridas com o ganho de peso (PBi/GP e LISi/ GP, respectivamente), de acordo com as fases experimentais e a dieta oferecida

Table 4 - Protein intake (CPB) and ratio of the protein and lysine intake to weight gain (PBi/GP and LISi/GP, respectively), according to the experimental phases and offered diets

\begin{tabular}{|c|c|c|c|c|c|c|c|c|c|}
\hline \multirow[t]{2}{*}{$\begin{array}{l}\text { Dietas } \\
\text { Diets }\end{array}$} & \multicolumn{3}{|c|}{$\begin{array}{l}1 \text { a } 21 \text { dias } \\
1 \text { to } 21 \text { days }\end{array}$} & \multicolumn{3}{|c|}{$\begin{array}{c}22 \text { a } 49 \text { dias } \\
22 \text { to } 49 \text { days }\end{array}$} & \multicolumn{3}{|c|}{$\begin{array}{l}1 \text { a } 49 \text { dias } \\
1 \text { to } 49 \text { days }\end{array}$} \\
\hline & $\begin{array}{c}\text { CPB } \\
(\mathrm{g})\end{array}$ & $\begin{array}{l}\mathrm{PBi} / \mathrm{GP} \\
(\mathrm{g} / \mathrm{g})\end{array}$ & $\begin{array}{l}\text { LISi/GP } \\
(\mathrm{g} / \mathrm{g})\end{array}$ & $\begin{array}{c}\text { CPB } \\
(\mathrm{g})\end{array}$ & $\begin{array}{c}\mathrm{PBi} / \mathrm{GP} \\
(\mathrm{g} / \mathrm{g})\end{array}$ & $\begin{array}{l}\text { LISi/GP } \\
(\mathrm{g} / \mathrm{g})\end{array}$ & $\begin{array}{c}\text { CPB } \\
(\mathrm{g})\end{array}$ & $\begin{array}{c}\text { PBi/GP } \\
(\mathrm{g} / \mathrm{g})\end{array}$ & $\begin{array}{l}\text { LISi/GP } \\
\quad(\mathrm{g} / \mathrm{g})\end{array}$ \\
\hline $\begin{array}{l}\text { Controle } \\
\text { Control }\end{array}$ & $238 b$ & $0,32 \mathrm{ab}$ & $0,0169 b c$ & $787 \mathrm{ab}$ & $0,40 \mathrm{ab}$ & 0,0199b & $1025 b$ & $0,38 b$ & $0,0191 b$ \\
\hline $\begin{array}{l}\text { BaixaPB-12\%AA } \\
\text { LowCP-12\%AA }\end{array}$ & $206 d$ & $0,31 \mathrm{ab}$ & $0,0166 \mathrm{c}$ & $657 c$ & $0,35 \mathrm{c}$ & $0,0183 \mathrm{c}$ & $863 c$ & $0,34 \mathrm{~d}$ & $0,0178 \mathrm{c}$ \\
\hline $\begin{array}{l}\text { AltaPB+20\%AA } \\
\text { HighCP+20\%AA }\end{array}$ & $252 \mathrm{a}$ & $0,33 \mathrm{a}$ & $0,02 \mathrm{a}$ & $832 \mathrm{a}$ & $0,42 \mathrm{a}$ & $0,0233 a$ & $1084 a$ & $0,40 \mathrm{a}$ & $0,0224 a$ \\
\hline $\begin{array}{l}\text { Livre escolha } \\
\text { Free choice }\end{array}$ & $221 \mathrm{c}$ & $0,31 b$ & $0,0179 b$ & $762 b$ & $0,38 b$ & $0,0204 b$ & $983 b$ & $0,36 \mathrm{c}$ & $0,0198 b$ \\
\hline & & & & & Sexo & Sex) & & & \\
\hline $\begin{array}{l}\text { Fêmea } \\
\text { Female }\end{array}$ & $222 \mathrm{a}$ & 0,32 & 0,0179 & $736 a$ & $0,40 \mathrm{a}$ & $0,012 \mathrm{a}$ & $959 a$ & $0,38 \mathrm{a}$ & $0,0203 \mathrm{a}$ \\
\hline $\begin{array}{l}\text { Macho } \\
\text { Male }\end{array}$ & $236 b$ & 0,32 & 0,0178 & $783 b$ & $0,38 b$ & $0,0198 b$ & $1019 b$ & $0,36 \mathrm{~b}$ & $0,0193 b$ \\
\hline
\end{tabular}

Médias seguidas por letras distintas na mesma coluna diferem $(P<0,05)$ pelo teste Tukey.

Averages followed in the column followed by different letters differ $(P<.05)$ by Tukey test.

$\mathrm{PBi} / \mathrm{GP}=$ relação da proteína bruta ingerida $(\mathrm{g})$ com ganho de peso $(\mathrm{g})$.

Crude protein intake $(g)$ to weight gain $(g)$ ratio.

LISi/GP: relação da lisina ingerida $(\mathrm{g})$ com ganho de peso $(\mathrm{g})$.

Lysine intake $(g)$ to weight gain $(g)$ ratio. 
Tabela 5 - Ganho de gordura e proteína corporal, peito, pernas e carcaça de frangos de corte de 1 a 49 dias de idade

Table 5 - Fat and protein gain, breast, legs and carcass of broilers from 1 to 49 days of age

\begin{tabular}{lccccc}
\hline $\begin{array}{l}\text { Dietas } \\
\text { Diets }\end{array}$ & $\begin{array}{c}\text { Gordura } \\
(\mathrm{g})\end{array}$ & $\begin{array}{c}\text { Proteína } \\
(\mathrm{g})\end{array}$ & $\begin{array}{c}\text { Peito } \\
(\mathrm{g})\end{array}$ & $\begin{array}{c}\text { Pernas } \\
(\mathrm{g})\end{array}$ & $\begin{array}{c}\text { Carcaça } \\
(\mathrm{g})\end{array}$ \\
\hline $\begin{array}{l}\text { Fat } \\
\text { Controlein }\end{array}$ & 448 & $553 \mathrm{a}$ & $625 \mathrm{a}$ & $631 \mathrm{a}$ & $2463 \mathrm{a}$ \\
$\begin{array}{l}\text { Control } \\
\text { BaixaPB-12\%AA }\end{array}$ & 452 & $501 \mathrm{~b}$ & $560 \mathrm{~b}$ & $606 \mathrm{a}$ & $2287 \mathrm{~b}$ \\
$\begin{array}{l}\text { LowCP-12\%AA } \\
\text { AltaPB+20\%AA }\end{array}$ & 429 & $577 \mathrm{a}$ & $656 \mathrm{a}$ & $615 \mathrm{a}$ & $2467 \mathrm{a}$ \\
$\begin{array}{l}\text { HighCP+20\%AA } \\
\text { Livre escolha }\end{array}$ & 432 & $556 \mathrm{a}$ & $612 \mathrm{ab}$ & $636 \mathrm{a}$ & $2449 \mathrm{a}$ \\
\begin{tabular}{l} 
Freechoice \\
\hline $\begin{array}{l}\text { Fêmea } \\
\text { Female }\end{array}$
\end{tabular} & 444 & $519 \mathrm{~b}$ & 602 & $573 \mathrm{~b}$ & $2276 \mathrm{~b}$ \\
$\begin{array}{l}\text { Macho } \\
\text { Male }\end{array}$ & 437 & $575 \mathrm{a}$ & 624 & $671 \mathrm{a}$ & $2557 \mathrm{a}$ \\
\hline
\end{tabular}

Médias seguidas por letras distintas na mesma coluna diferem pelo teste Tukey $(\mathrm{P}<0,05)$.

Averages in the column followed by different letters differ $(P<.05)$ by Tukey test.

com relações calórico-protéicas mais estreitas proporcionam carcaças mais magras (Leeson \& Summers, 1997; Bartov, 1998; Bartov \& Plavnik, 1998). Neste estudo, este efeito foi mais evidente para ganho de proteína que de gordura (Tabela 5). As aves com livre escolha não diferiram daquelas do tratamento controle. Machos e fêmeas tiveram ganhos semelhantes em gordura e peito, mas os primeiros apresentaram maior ganho em proteína, além de carcaças e pernas mais pesadas.

\section{Conclusões}

O aumento de proteína e de aminoácidos na dieta, mantendo a mesma energia não alterou o desempenho das aves em comparação à dieta controle. No entanto, o decréscimo em proteína e aminoácidos reduziu o desempenho dos animais. As aves foram mais sensíveis à deficiência de aminoácidos e proteína na fase inicial.

Aves com livre escolha alcançaram desempenho semelhante às do grupo controle, ao escolherem dietas um pouco menos protéicas, porém mais ricas em aminoácidos essenciais. Os machos foram mais eficientes que as fêmeas em utilizar os nutrientes consumidos.

\section{Literatura Citada}

ASSOCIATION OF OFFICIAL ANALYTICAL CHEMISTS AOAC. Official methods of analysis. 15.ed. Washington, D.C.: 1990. 972p.

BARTOV, I. Lack of interrelationship between the effects of dietary factors and food withdrawal on carcass quality of broiler chickens. British Poultry Science, v.39, p.426-433, 1998.

BARTOV, I.; PLAVNIK, I. Moderate excess of dietary protein increases breast meat yield of broilers chicks. Poultry Science, v.77, p.680-688.1998, 1998.

BORGES, A.F.; OLIVEIRA, R.F.; DONZELE, J.L. et al. Exigência de lisina para frangos de corte machos no período de 22 a 42 dias de idade, mantidos em ambiente quente $\left(26^{\circ} \mathrm{C}\right)$. Revista Brasileira de Zootecnia, v.31, n.5, p.1993-2001, 2002.

JACKSON, S.; SUMMERS, J.D.; LEESON, S. Effect of dietary protein and energy on broiler carcass composition and efficiency of nutrient utilization. Poultry Science, v.61, p.2224-2231, 1982.

KESSLER, A.M. Programas alimentares para otimizar a deposição de carne e gordura em carcaças de frangos de corte. In: RIBEIRO, A.M.L.; BERNARDI, M.L; KESSLER, A.M. (Eds.) Tópicos em produção animal I. Porto Alegre: Universidade Federal do Rio Grande do Sul, 1999. p.183-199.

LEESON, S.; SUMMMERS, J.D. Commercial poultry nutrition. 2.ed. Guelph: University Books, 1997. 350p.

NATIONAL RESEARCH COUNCIL - NRC. Nutrient requirements of poultry. Washington, D.C.: National Academy of Science, 1994. p.27.

REGINATTO, M.F.; RIBEIRO, A.M.L.; PENZ JR., A.M. et al. Efeito da energia, relação energia:proteína e fase de crescimento sobre o desempenho e composição de carcaça de frangos de corte. Revista Brasileira Ciência Avícola, v.2, n.3, p.229-237, 2000.

ROSEBROUGH, R.W.; STEELE, N.C. Energy and protein relationships in the broiler. 1. Effect of protein levels and feeding regimens on growth, body composition, and in vitro lipogenesis of broiler chicks. Poultry Science, v.64, p.119-126, 1985.

SCHUTTE, J.B.; PACK, M. Sulfur amino acid requirement of broiler chicks from 14 to 38 days of age. 1. Performance and carcass yield. Poultry Science, v.74, p.480-487, 1995.

ANALYTICAL SOFTWARE. Statistix for windows - user's manual. Tallahassee: 1996. 333p.

SHARIATMADARI, F.; FORBES, J.M. Growth and food intake responses to diets of different protein contents and a choice between diets containing two concentrations of protein in broilers and layer strains of chicken. British Poultry Science, v.34, p.959-970, 1993.

SUMMERS, J.D.; LEESON, S.; SPRATT, D. Yield and composition of edible meat from male broilers as influenced by dietary protein level and amino acid supplementation. Canadian Journal Animal Science, v.68, p.241-248, 1988.

YO, T.; SIEGELP, B.; FAURE, J. M. et al. Self-selection of dietary protein and energy by broilers growth under a tropical climate: adaptation when exposed by choice feeding at different ages. Poultry Science, v.77, n.4, p.502-508, 1998.

Recebido em: 27/05/03 Aceito em: 18/11/04 